\title{
A Polycyclic Aromatic Hydrocarbon Containing A Pyrrolopyridazine Core
}

\author{
Marcus Richter, ${ }^{[a]}$ Yubin Fu, ${ }^{[a]}$ Evgenia Dmitrieva, ${ }^{[b]}$ Jan J. Weigand, ${ }^{[c]}$ Alexey Popov, ${ }^{[b]}$ Reinhard \\ Berger, ${ }^{[a]}$ Junzhi Liu, ${ }^{[a]}$ Xinliang Feng ${ }^{*[a]}$
}

\begin{abstract}
Polycyclic aromatic azomethine ylide (PAMY) is a versatile building block for the bottom-up construction of unprecedented nitrogen-containing polycyclic aromatic hydrocarbons (N-PAHs). Here, we demonstrate the 1,3-dipolar cycloaddition between PAMY and 1,4-diphenylbut-2-yne-1,4-dione as well as the subsequent condensation reaction with hydrazine, which led to synthesis of unique N-PAHs with a phenyl-substituted pyrrolopyridazine core (PP-1 and PP-2). The molecular structures of pristine PP-1 and tert-butyl-substituted PP-2 were verified by NMR and mass spectroscopy. Moreover, the structure of PP-2 was unambiguously elucidated by X-ray single crystal analysis. The optoelectronic properties were investigated by solvent-dependent UV-Vis absorption and fluorescence emission spectroscopy as well as cyclic voltammetry. Additionally, the density functional theory (DFT) calculations exhibited a push-pull behavior for PP-1 and PP-2. Furthermore, the in situ EPR/UV-Vis-NIR spectroelectrochemistry allowed the detailed insight into the spectroscopic properties and spin distribution of radical cation species of PP-2.
\end{abstract}

Due to their potential applications in nano- and optoelectronics, the interest in polycyclic aromatic hydrocarbons (PAHs) has increased throughout the last two decades. ${ }^{[1]}$ However, the electronic structure and optical properties of PAHs highly depend on their size, geometry and periphery substitution. ${ }^{[2]}$ The introduction of heteroatoms, like nitrogen, into the $s p^{2}$-hybridized polycyclic aromatic framework is a further effective strategy to tailor their intrinsic physical and chemical properties, such as decreasing the lowest unoccupied molecular orbital (LUMO) level, rendering binding sites to metal atoms, or stabilizing oxidized as well as reduced species. ${ }^{[3]}$ In particular, the amount and the precise position of the nitrogen atom significantly influence the electronic features of nitrogen-containing PAHs (N$\mathrm{PAHs}$, Figure 1). For example, the introduction of nitrogen atoms

[a] M. Richter, Y. Fu, Dr. R. Berger, Dr. J. Liu, Prof. Dr. X. Feng Dresden University of Technology, Center for Advancing Electronics Dresden (cfaed), Faculty of Chemistry and Food Chemistry, Institute for Molecular Functional Materials Mommsenstraße 4, 01069 Dresden, Germany E-mail: xinliang.feng@tu-dresden.de

[b] Dr. E. Dmitrieva, Dr. A. Popov Leibniz Institute for Solid State and Materials Research, Nanoscale Chemistry

Center of Spectroelectrochemistry

Helmholtzstrasse 20, 01069 Dresden, Germany

[c] Prof. Dr. J. J. Weigand

Dresden University of Technology, Faculty of Chemistry and Food Chemistry

Institute of Inorganic Molecular Chemistry

Mommsenstraße 4, 01069 Dresden, Germany

Supporting information for this article is given via a link at the end of the document.((Please delete this text if not appropriate)) into the periphery, like in azapentacene I or tetraazaperylene derivate II, offers electron-deficient N-PAHs. ${ }^{[4]}$ In contrast, the internal implementation of nitrogen atoms into the pristine carbon framework via a pyrrole ring, such as in pyrrole-fused azacoronene III or hydrazine-embedded buckybowl IV, leads to electron-rich N-PAHs. ${ }^{[5]}$ Nevertheless, it remains challenging to incorporate nitrogen atoms selectively and precisely in the basal plane of PAHs. ${ }^{[6]}$

One attractive building block for the synthesis of novel N-PAHs is the polycyclic aromatic azomethine ylide (PAMY), which was first developed by our group. ${ }^{[7]}$ Besides the dimerization of PAMYs to pyrazine-embedded PAHs at high temperatures, the zwitterionic character enables the 1,3-dipolar cycloaddition at room temperature, which serves as an efficient strategy for the synthesis of pyrrole-incorporated PAHs. ${ }^{[7-8]}$ Recently, our group, as well as Ito's group, extended the range of dipolarophiles and reported on the cycloaddition of PAMYs with asymmetric or pristine carbon dipolarophiles, such as 1,2-naphthoquinone and coronene, respectively. ${ }^{[9]}$

Herein, we present the synthesis of unprecedented N-PAHs containing a diphenyl-substituted pyrrolopyridazine core (PP-1 and PP-2) via cycloaddition with PAMY as key step, and subsequent condensation with hydrazine. Furthermore, we broadened the variety of dipolarophiles for cycloaddition with PAMY and showed 1,4-diphenylbut-2-yne-1,4-dione 2 as versatile dipolarophile. Besides the verification with NMR spectroscopy and mass spectrometry, the structure of tert-butyl substituted PP-2 was unambiguously confirmed by X-ray single crystal analysis. The investigations of the optoelectronic properties were performed via UV-Vis absorption, fluorescence emission spectroscopy and cyclic voltammetry. Density functional theory (DFT) calculations indicated an intramolecular push-pull behavior caused by the ullazine unit as donor and the pyridazine core as acceptor. Moreover, the pronounced oxidation behavior allowed the formation of the radical cation species of PP-2 as probed by in situ EPR/UV-Vis-NIR spectroelectrochemistry.
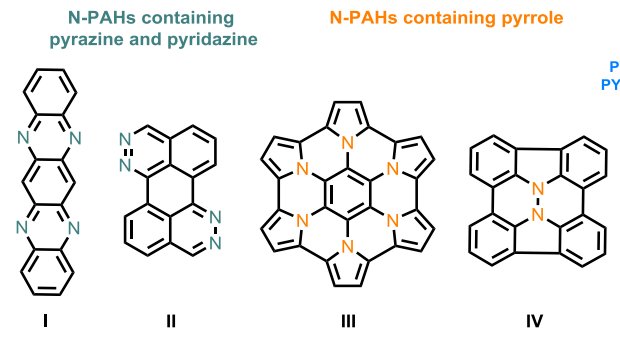

current work

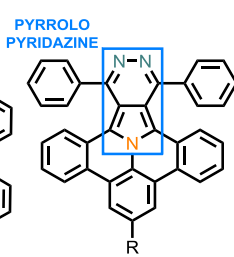

PP-1: $\mathrm{R}_{1}=\mathrm{H}$ PP-2: $R_{2}={ }^{\prime} B u$

Figure 1. Several examples of N-PAHs (I-IV) in comparison to PP-1 and PP- 
2. For better visualization, the substituents of I-IV are obscured.

The targeted compounds PP-1 and PP-2 were synthesized in two steps starting from $8 H$-isoquinolino[4,3,2de]phenanthridinium tetrafluoroborate (1a) and 2-(tert-butyl)-8Hisoquinolino[4,3,2-de]phenanthridinium tetrafluoroborate (1b), respectively (see Scheme 1). ${ }^{[7-8]} \quad$ Intermediates benzo[7,8]indolizino[6,5,4,3-def]phenanthridine-1,2-

diyl)bis(phenylmethanone) (3a) and (8-(tertbutyl)benzo[7,8]indolizino[6,5,4,3-def]phenanthridine-1,2-

diyl)bis(phenylmethanone) (3b) were obtained via 1,3-dipolar cycloaddition of PAMY, which was generated by the addition triethylamine (TEA) from the iminium salts $\mathbf{1 a}$ and $\mathbf{1 b}$, respectively, and 1,4-diphenylbut-2-yne-1,4-dione (2) as dipolarophile with subsequent dehydrogenation using 2,3dichloro-5,6-dicyano-1,4-benzoquinone (DDQ). After this one pot synthesis, the ketone compounds $\mathbf{3 a}$ and $\mathbf{3 b}$ were obtained in $88 \%$ and $86 \%$ yield, respectively. The following condensation with hydrazine and purification via methanol precipitation gave the final compounds 1,4 diphenylbenzo[7,8]pyridazino[4',5':1,2]indolizino[6,5,4,3-

deffphenanthridine (PP-1) and 10-(tert-butyl)-1,4diphenylbenzo[7,8]pyridazino[4',5':1,2]indolizino[6,5,4,3-

deffphenanthridine (PP-2) as yellow solids in $66 \%$ and $83 \%$ yield, respectively. All intermediates and target compounds were fully characterized by high-resolution (HR) atmospheric pressure chemical ionization (APCl) or HR electrospray ionization (ESI) mass spectrometry as well as NMR spectroscopy.

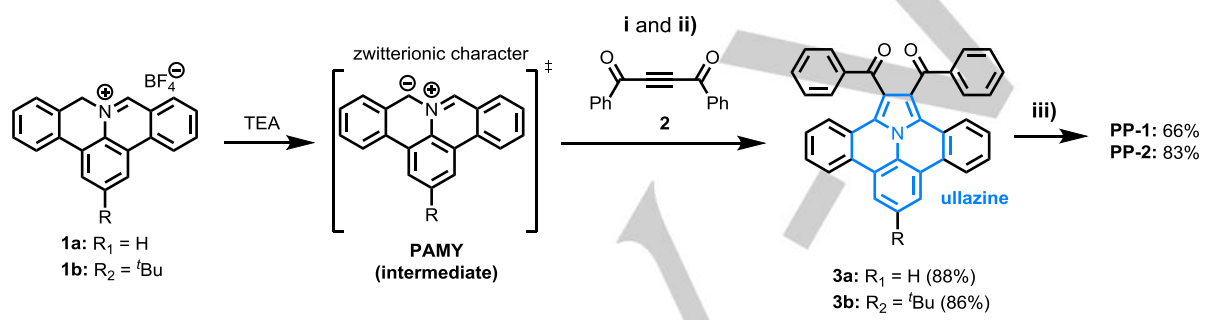

Scheme 1. Synthetic route towards PP-1 and PP-2. Reagents and conditions: i) 1,4-diphenylbut-2-yne-1,4-dione, DCM, 5 min, r.t. ii) DDQ, toluene, r.t., 3h. iii) hydrazine, ethanol, overnight, $80^{\circ} \mathrm{C}$.

The single crystal of PP-2 was obtained by slow diffusion of methanol into a diethyl ether solution of PP-2. The structure of PP-2 was unambiguously determined by X-ray single-crystal diffraction analysis (Figure 2). The single crystal of PP-2 showed a planar ullazine motif and a twisted pyridazine ring in an angle of $121^{\circ}$ as well as twisted phenyl substituents in an angle of $52^{\circ}$ (Figure 2a). In the pyridazine unit, the lengths of the $\mathrm{N}-\mathrm{N}(\mathrm{A})$ and C-N (B) bonds are $1.36 \AA$ and $1.32 \AA$, respectively (Figure $2 b$ ). Moreover, in the pyrrole core, $\mathrm{C}-\mathrm{N}(\mathrm{F})$ bond length is $1.39 \AA$ and the $\mathrm{C}-\mathrm{C}$ bond lengths are 1.41 and $1.43 \AA$, respectively (Figure $2 b)$. The bond lengths of the pyrrole and pyridazine motifs are in agreement with the literature values. ${ }^{[4 c, 7,9 a]}$ Crystals of PP-2 are arranged in a brick-wall fashion with $\pi-\pi$ distance of $3.40 \AA$ between neighboring molecules (Figure 2c). 
a)

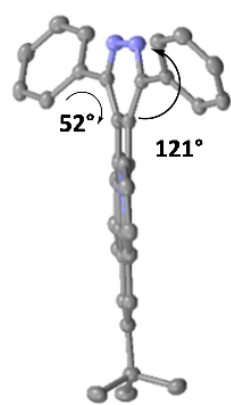

b)

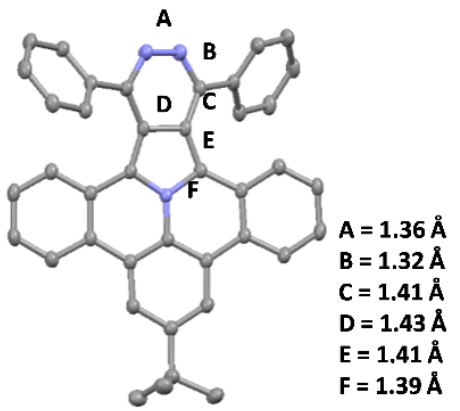

c)

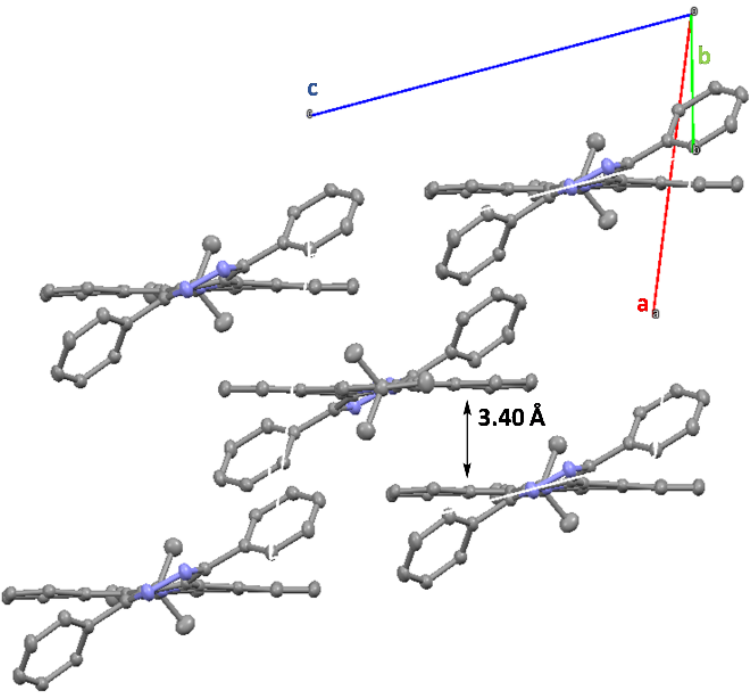

Figure 2. (a) Side view of the single crystal structure of PP-2. (b) Top view of the single crystal structure of PP-2. (c) The crystal packing of PP-2.

The optical properties of PP-1 and PP-2 were investigated by solvent-dependent UV-Vis absorption and fluorescence emission spectroscopy in acetonitrile (ACN), dichloromethane (DCM), diethy lether $\left(\mathrm{Et}_{2} \mathrm{O}\right)$ and toluene. In the UV-Vis absorption as well as fluorescence emission spectra, there is no difference between PP-1 and PP-2, which confirmed that the tert-butyl substituent does not apparently influence the optoelectronic properties (see SI). As a typical example, the solvent-dependent UV-Vis absorption spectra of PP-2 are shown in Figure 3a. The solutions of PP-2 in toluene and $\mathrm{Et}_{2} \mathrm{O}$ exhibit an intensive broad absorption band between 400 and $500 \mathrm{~nm}$ with absorption maxima ( $\lambda_{\max }$ abs) at $433 \mathrm{~nm}$ and $428 \mathrm{~nm}$, respectively. In more polar solvents such as ACN and DCM, the absorption spectra are better resolved and the $\lambda_{\max }$, abs of PP-2 revealed a hypsochromic shift up to $14 \mathrm{~nm}$ in ACN. The optical energy gap $\left(\Delta E_{\mathrm{g}}{ }^{\mathrm{opt}}\right)$ of PP-2 calculated from the absorption maximum of UV-Vis absorption spectrum in DCM is $2.93 \mathrm{eV}$. In contrast, the emission maximum ( $\lambda_{\max }$ ems $)$ of PP-2 is observed at $560 \mathrm{~nm}$ showed no solvent-dependency (see SI). The fluorescence quantum yield $(\Phi)$ determined for PP-2 is $\Phi=0.22$ in DCM (see SI). ${ }^{[10]}$ The electrochemical properties of PP-2 were further investigated by cyclic voltammetry (CV) which allowed the determination of the energy levels of the frontier orbitals. In DCM, PP-2 showed a reversible oxidation wave $(0.5 \mathrm{~V}$ vs
$\mathrm{Fc}^{+} / \mathrm{Fc}$ ), which becomes irreversible if further redox processes occur (see Figure 3b). Additional, two further overlapping oxidation waves were detected (Figure $3 b$ ). A reduction behavior was not observed in the available potential window (see SI). Thus the highest occupied molecular orbital (HOMO) was estimated based on the half-wave potential of the first reversible oxidation to be $-5.30 \mathrm{eV}$. The lowest unoccupied molecular orbital (LUMO), which was deduced by the optical band gap and electrochemical HOMO level, is $-2.37 \mathrm{eV}$. All calculated optoelectronic data of PP-1 and PP-2 are summarized in the SI.
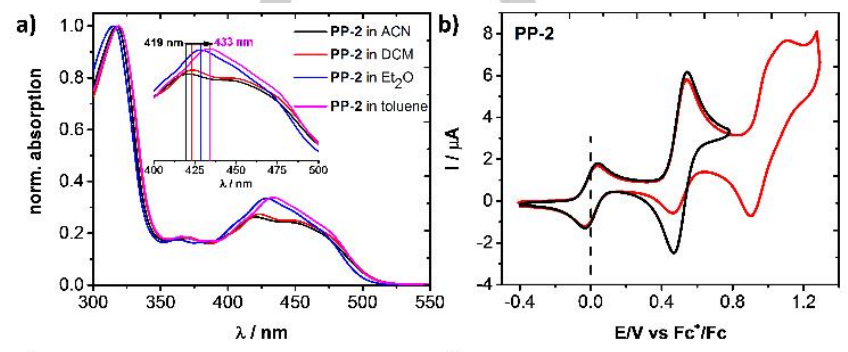

c)
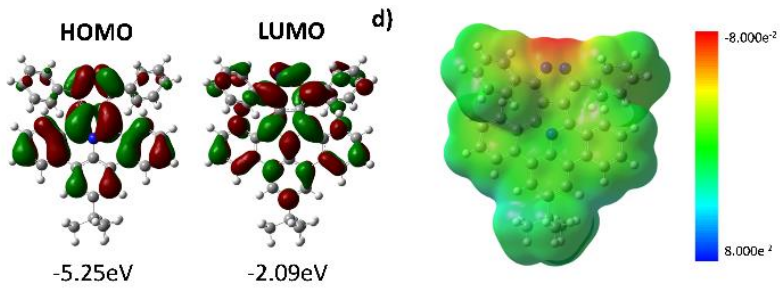

Figure 3. (a) Solvent-dependent UV-Vis absorption spectra of PP-2 in acetonitrile $(\mathrm{ACN})$, dichloromethane $(\mathrm{DCM})$, diethyl ether $\left(\mathrm{Et}_{2} \mathrm{O}\right)$ and toluene. Inset: zoom of the solvent-dependent UV-Vis absorption spectra of PP-2 from 400 to $500 \mathrm{~nm}$. (b) Cyclic voltammogram of PP-2 recorded in DCM with $0.1 \mathrm{M}$ $n$-Bu $\mathrm{NPF}_{6}$ as a supporting electrolyte at $100 \mathrm{mVs}^{-1}$ from $-0.4 \mathrm{~V}$ to $0.8 \mathrm{~V}$ (black line) and $-0.4 \mathrm{~V}$ to $1.3 \mathrm{~V}$ (red line). AgCl-coated Ag-wire was used as a reference electrode, platinum as a working electrode and Pt-wire as a counter electrode. (c) Calculated molecular orbitals and energy level of PP-2 with a B3PW91 functional and 6-31G*basis set (HOMO level: left; LUMO level: right). (d) ESP calculation of PP-2 (red: negative charge distribution and blue: positive charge distribution).

The electronic ground states of PP-1 and PP-2 were investigated by density functional theory (DFT) with a Gaussian 09 package. The geometry of PP-1 and PP-2 was optimized by the B3PW91/6-31G* based on the single crystal structure. The graphical representations of the HOMO and the LUMO are presented in Figure 3c exemplified for PP-2. The HOMO mainly distributed at the dibenzoullazine motif and partially at the pyridazine core as well as phenyl substituents (see $\mathrm{SI}$ ). In contrast, the LUMO equally delocalized over the full $\pi$-system. The calculated HOMO levels (PP-1: $-5.28 \mathrm{eV}$; PP-2: $-5.25 \mathrm{eV}$ ) are in agreement with the experimental derived value (PP-2: $-5.30 \mathrm{eV}$ ) from CV measurements. Furthermore, the calculated energy gaps (PP-1: $3.17 \mathrm{eV}$; PP-2: $3.16 \mathrm{eV}$ ) are in accordance with the optical energy gap $(2.93 \mathrm{eV})$. For a deeper insight into the electronic nature, electronic static potential (ESP) were investigated (PP-1: SI and PP-2: Figure 3d). PP-2 revealed a neutral charge distribution over the whole structure (green color). Negative charge distribution (red color) was found in the pyridazine unit which can be explained by the localization of the 
lone pairs of electrons and the higher electronegativity of the nitrogen atoms. The structure with a pyridazine core as acceptor and the ullazine unit as donor explains the push-pull behavior. ${ }^{[11]}$ Furthermore, anisotropy of the induced current density (ACID) calculations were performed to verify the aromatic features and confirmed the global aromaticity of the PP-1 and PP-2 (see SI).
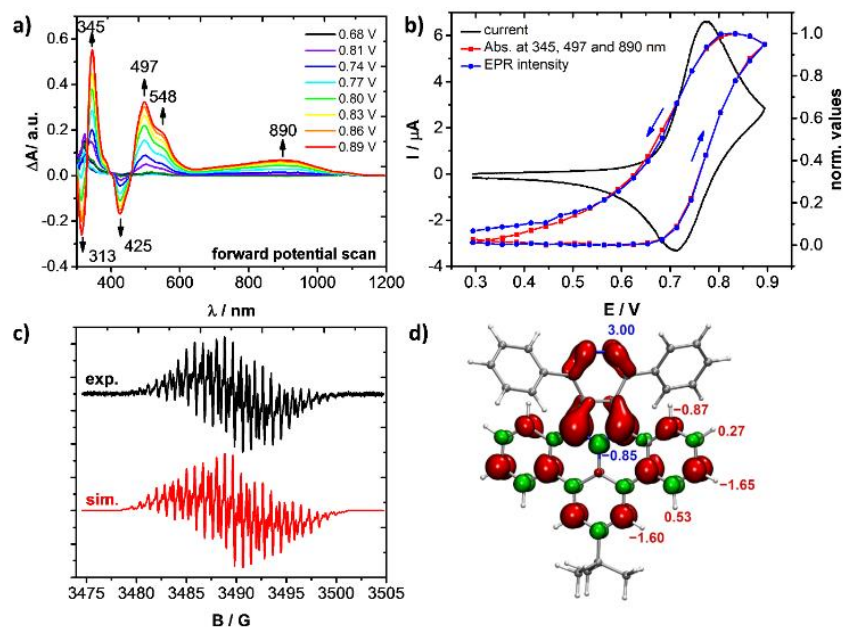

d)

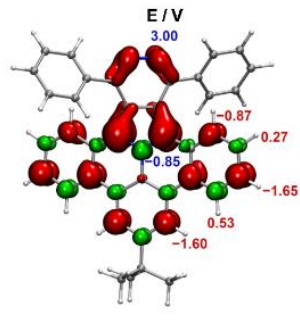

Figure 4. In situ EPR/UV-Vis-NIR spectroelectrochemical measurement of PP-2. (a) UV-Vis-NIR absorption spectra measured during the electrochemical oxidation of PP-2. (b) Black: cyclic voltammogram of the oxidation (0.1 M $n$-Bu4 $\mathrm{NPF}_{6}$ in $\mathrm{DCM}$, scan rate $\left.=5 \mathrm{mVs}^{-1}\right)$. Red: potential dependence of UV-Vis-NIR absorption bands $(\lambda=345,497$ and $890 \mathrm{~nm})$. Blue: potential dependence of double integrated EPR intensity. (c) Experimental and simulated EPR spectra of PP-2*+. (d) DFT-computed spin density distribution in the radical cation $\mathbf{P P}-2^{\bullet+}$ along with hyperfine coupling constants obtained from the fit of experimental EPR spectrum (the sign and the values are assigned to different types of atoms based on B3LYP functional with EPR-III basis set for $\mathrm{N}$ and $\mathrm{H}$ atoms, and TZVP basis set for carbons, Orca package ${ }^{[12]} ; a\left({ }^{14} \mathrm{~N}\right)$ constants are shown in dark blue, $a\left({ }^{1} \mathrm{H}\right)$ constants - in red).

The protonation of PP-1 and PP-2 with triflic acid (TfOH) was performed and monitored via NMR spectroscopy, HR matrixassisted laser desorption/ionization (MALDI) time of flight (ToF) MS and UV-Vis absorption titration (see SI). Furthermore, in situ electron paramagnetic resonance (EPR) and UV-Vis-nearinfrared (NIR) absorption spectroscopy enable the detailed investigation of the radical species of PP-2. The spectroelectrochemical results of PP-2 are displayed in Figure 4. Upon the oxidation, UV-Vis-NIR absorption spectra manifest new absorption maxima at 345, 497, 548 and $890 \mathrm{~nm}$ (Figure 4a). The potential profiles of the absorption bands and the EPR intensity are identical (Figure $4 b)$. Thus, the emerging absorption bands can be obviously attributed to the radical cation PP-2 ${ }^{\circ+}$. EPR spectrum of radical cation PP-2 ${ }^{\circ+}$ shows a well resolved hyperfine structure due to the interaction of the unpaired electron spin with nuclei spins of nitrogen and protons (Figure 4c). DFT calculations demonstrate that the spin density is delocalized over the whole framework and no spin density is delocalized at the phenyl-substituents. The largest coupling constants are predicted for the N-N bond and for protons at the perimeter of the $\mathrm{PAH}$. For a more precise interpretation of the hyperfine pattern, the spectrum is fitted using EasySpin software ${ }^{[13]}$ and DFT-derived hyperfine ${ }^{[12]}$ coupling constant as starting values. Perfect match to the experimental data is obtained for $2 \times a\left({ }^{14} \mathrm{~N}\right)$ of $3.00 \mathrm{G}$, the internal nitrogen with a constant of $-0.85 \mathrm{G}$, and five couples of protons with $a\left({ }^{1} \mathrm{H}\right)$ constants of $-1.65,-1.60,-0.87,0.83$, and $0.27 \mathrm{G}$ (Figure $4 \mathrm{~d}$ ). Comparable hfc constant for all protons on the perimeter of the $\mathrm{PAH}$ core as well as considerable hfc values for nitrogen atoms prove delocalization of the spin density in radical cation (and hence also the HOMO in the pristine PP-2) over the whole aromatic moiety.

In summary, we have demonstrated an efficient two-step synthesis of the first diphenyl-substituted pyrrolopyridazine-coreembedded N-PAHs via one-pot 1,3-dipolar cycloaddition and dehydrogenation as well as subsequent condensation with hydrazine. The chemical identities were elucidated by NMR spectroscopy, MS and X-ray single crystal analysis for PP-2, which revealed a twisted pyridazine ring with a N-N bond length of $1.36 \AA$. An intramolecular push-pull behavior between the ullazine as donor and the pyridazine core as acceptor unit within PP-1 and PP-2 was confirmed by DFT calculations. Furthermore, in situ EPR/UV-Vis-NIR spectroelectrochemistry showed the formation of radical cation species PP-2.+ with broad NIR absorption maximum at $890 \mathrm{~nm}$. PP-1 and PP-2 could be material candidates for organic field effect transistor (OFET) applications or chemical/bio sensing.

\section{Experimental Section}

The synthesis and the analytical data of $8 \mathrm{H}$-isoquinolino[4,3,2de]phenanthridinium tetrafluoroborate (1a) and 2-(tert-butyl)- $8 \mathrm{H}$ isoquinolino[4,3,2-de]phenanthridinium tetrafluoroborate (1b) were reported in our previous work. ${ }^{[7-8]}$

General procedure for the synthesis of the intermediates (3a and 3b)

In a dry and inert Schlenk tube the iminium salt (1.00 eq.) and 1,4diphenyl-2-butyne-1,4-dione (2, $173 \mathrm{mg}, 739 \mu \mathrm{mol}, 1.20$ eq.) were dissolved in anhydrous dichloromethane (DCM, $20 \mathrm{ml})$. Anhydrous triethylamine $(7.4 \mathrm{mmol}$, $12.00 \mathrm{eq})$ was added under stirring in one portion. The reaction was stirred for several minutes and transferred to a round-bottom flask afterwards. Solvents and residual triethylamine were removed under reduced pressure to obtain the crude product. 2,3Dichloro-5,6-dicyano-1,4-benzoquinone (DDQ, 559 mg, $2.47 \mathrm{mmol}$, 4.00 eq.) was added and the flask was sealed with a septum as well as purged with argon for five minutes. Anhydrous toluene $(20 \mathrm{ml})$ was added via syringe. After 30 minutes, the reaction was quenched by addition of water $(10 \mathrm{ml})$ and extracted with DCM $(20 \mathrm{ml})$ five times. The combined organic layers were washed with brine and dried over magnesium sulfate. The solvent was removed under reduced pressure. The residue was dissolved in a minimum amount of DCM $(10 \mathrm{ml})$ and precipitated in methanol $(300 \mathrm{ml})$. The precipitate was filtered.

3a: $\mathrm{M}_{\mathrm{p}}=360^{\circ} \mathrm{C} .{ }^{1} \mathrm{H}-\mathrm{NMR}\left(600 \mathrm{MHz}, \mathrm{C}_{2} \mathrm{D}_{2} \mathrm{Cl}_{4}\right): \delta=8.39(\mathrm{~d}, J=8.1 \mathrm{~Hz}$ $2 \mathrm{H}), 8.34(\mathrm{~d}, J=8.1 \mathrm{~Hz}, 2 \mathrm{H}), 7.95(\mathrm{dd}, J=8.2,0.6 \mathrm{~Hz}, 2 \mathrm{H}), 7.71$ (t, $J=$ $8.0 \mathrm{~Hz}, 1 \mathrm{H}), 7.53(\mathrm{dd}, J=8.2,1.1 \mathrm{~Hz}, 4 \mathrm{H}), 7.49-7.45(\mathrm{~m}, 2 \mathrm{H}), 7.42$ (dd, $J=10.6,4.2 \mathrm{~Hz}, 2 \mathrm{H}), 7.32-7.26(\mathrm{~m}, 2 \mathrm{H}), 7.21$ (t, $J=7.8 \mathrm{~Hz}, 4 \mathrm{H}) \mathrm{ppm}$. ${ }^{13} \mathrm{C}-N M R$ (151 MHz, $\left.\mathbf{C}_{2} \mathrm{D}_{2} \mathrm{Cl}_{4}\right): \delta 195.5,139.2,133.5,130.2,129.1$ $129.1,128.7,128.4,127.0,125.6,125.5,124.8,124.6,123.4,121.6$, 
$121.1 \mathrm{ppm}$. The recorded ${ }^{13} \mathrm{C}-\mathrm{NMR}$ spectrum of intermediate $3 \mathrm{a}$ displays 16 detectable peaks, which can be assigned to $9 \times \mathrm{CH}$ and $7 \times$ quarternary carbon atoms, respectively. The peak of one quarternary carbon could not resolve and is obviously overlapping. HR-MS (APCI-MS): $\mathrm{m} / \mathrm{z}$ $\left([\mathrm{M}+\mathrm{H}]^{+}\right)=500.1642$, calcd. for $\mathrm{C}_{36} \mathrm{H}_{22} \mathrm{NO}_{2}: \mathrm{m} / \mathrm{z}=500.1650 ;$ error $=-1.6$ ppm. IR: $\tilde{v}=2976,2903,1644,735,690 \mathrm{~cm}^{-1}$.

3b: $\mathrm{M}_{\mathrm{p}}=308^{\circ} \mathrm{C} .{ }^{1} \mathrm{H}-\mathrm{NMR}\left(600 \mathrm{MHz}, \mathrm{C}_{2} \mathrm{D}_{2} \mathrm{Cl}_{4}\right): \delta 8.42(\mathrm{~s}, 2 \mathrm{H}), 8.38(\mathrm{~d}, \mathrm{~J}=$ $8.2 \mathrm{~Hz}, 2 \mathrm{H}), 7.95(\mathrm{~d}, J=8.0 \mathrm{~Hz}, 2 \mathrm{H}), 7.53(\mathrm{dd}, J=8.2,1.0 \mathrm{~Hz}, 4 \mathrm{H}), 7.49$ $-7.45(\mathrm{~m}, 2 \mathrm{H}), 7.44-7.39(\mathrm{~m}, 2 \mathrm{H}), 7.32-7.25(\mathrm{~m}, 2 \mathrm{H}), 7.21(\mathrm{t}, J=7.8$ $\mathrm{Hz}, 4 \mathrm{H}), 1.52$ (s, 9H) ppm. ${ }^{13} \mathbf{C}-N M R\left(151 \mathbf{~ M H z}, \mathbf{C}_{2} \mathbf{D}_{2} \mathbf{C l}_{4}\right): \delta 195.5,148.4$, 139.2, 133.6, 130.1, 128.9, 128.7, 128.3, 127.3, 127.2, 125.7, 124.9, 124.5, 123.3, 122.9, 121.0, 118.6, 35.67, 32.1 ppm. HR-MS (APCI-MS): $\mathrm{m} / \mathrm{z}\left([\mathrm{M}+\mathrm{H}]^{+}\right)=556.2262$, calcd. for $\mathrm{C}_{40} \mathrm{H}_{30} \mathrm{NO}_{2}: \mathrm{m} / \mathrm{z}=556.2276$; error $=$ -2.5 ppm. IR: $\tilde{v}=2957,1641,753,695 \mathrm{~cm}^{-1}$.

\section{General procedure for the synthesis of N-PAHs with Pyrrolopyridazine Core (PP-1 and PP-2)}

In a dry and inert $50 \mathrm{ml}$ Schlenk flask, intermediate (3a or $\mathbf{3 b}$, 1.00eq.) and an excess of hydrazine monohydrate ( 5.00 eq.) was suspended in anhydrous ethanol $(20 \mathrm{ml})$. Afterwards, stirring was continued overnight at $78{ }^{\circ} \mathrm{C}$. After cooling down to room temperature, the reaction mixture was quenched with water and extracted with DCM $(20 \mathrm{ml})$ five times. The combined organic layers were washed with brine and dried over magnesium sulfate. The solvent was removed under reduced pressure and the residue was dissolved in a minimum amount of DCM $(\sim 10 \mathrm{ml})$ and precipitated in methanol $(300 \mathrm{ml})$ to obtain the target compounds as solids.

PP-1: $\mathrm{Mp}_{\mathrm{p}}=427^{\circ} \mathrm{C} .{ }^{1} \mathrm{H}-\mathrm{NMR}\left(600 \mathrm{MHz}, \mathrm{C}_{2} \mathrm{D}_{2} \mathrm{Cl}_{4}\right): \delta 8.50(\mathrm{~d}, J=8.0 \mathrm{~Hz}$, 2H), $8.35(\mathrm{~d}, J=8.1 \mathrm{~Hz}, 2 \mathrm{H}), 7.85(\mathrm{t}, J=7.9 \mathrm{~Hz}, 1 \mathrm{H}), 7.80-7.70(\mathrm{~m}$, $4 \mathrm{H}), 7.48$ (t, $J=7.4 \mathrm{~Hz}, 2 \mathrm{H}), 7.42$ (t, $J=7.4 \mathrm{~Hz}, 4 \mathrm{H}), 7.39$ (dd, $J=11.2$, $3.9 \mathrm{~Hz}, 2 \mathrm{H}), 7.21(\mathrm{~d}, J=8.0 \mathrm{~Hz}, 2 \mathrm{H}), 7.00(\mathrm{t}, J=7.6 \mathrm{~Hz}, 2 \mathrm{H}) \mathrm{ppm} .{ }^{13} \mathrm{C}-$ NMR (151 MHz, $\mathbf{C}_{2} \mathbf{D}_{2} \mathrm{Cl}_{4}$ ): $\delta$ 153.5, 139.4, 129.9, 129.2, 129.0, 128.1, $127.4,126.4,125.4,124.5,122.9,121.2,119.4 \mathrm{ppm}$. Due to the low solubility in $\mathrm{C}_{2} \mathrm{D}_{2} \mathrm{Cl}_{4}$ chemical shifts of $13-\mathrm{C}$ nuclei were derived from the HMBC experiment. Unfortunately, not all carbon atoms could be detected. HR-MS (APCI-MS): $\mathrm{m} / \mathrm{z}\left([\mathrm{M}+\mathrm{H}]^{+}\right)=496.1802$, calcd. for $\mathrm{C}_{36} \mathrm{H}_{22} \mathrm{~N}_{3}: \mathrm{m} / \mathrm{z}=496.1813$; error $=-1.8 \mathrm{ppm}$. IR: $\tilde{\mathrm{v}}=2979,2909,755$, $695 \mathrm{~cm}^{-1}$.

PP-2: $\mathrm{M}_{\mathrm{p}}=403^{\circ} \mathrm{C} .{ }^{1} \mathrm{H}-\mathrm{NMR}\left(600 \mathrm{MHz}, \mathrm{C}_{2} \mathrm{D}_{2} \mathrm{Cl}_{4}\right): \delta 8.52(\mathrm{~s}, 2 \mathrm{H}), 8.39(\mathrm{~d}$ $J=8.1 \mathrm{~Hz}, 2 \mathrm{H}), 7.85-7.66(\mathrm{~m}, 4 \mathrm{H}), 7.50-7.45(\mathrm{~m}, 2 \mathrm{H}), 7.40$ (ddd, $J=$ $15.4,11.5,4.4 \mathrm{~Hz}, 6 \mathrm{H}), 7.21-7.17(\mathrm{~m}, 2 \mathrm{H}), 7.01-6.97(\mathrm{~m}, 2 \mathrm{H}), 1.53(\mathrm{~s}$, 9H) ppm. ${ }^{13} \mathbf{C}-N M R\left(151 \mathbf{~ M H z}, \mathbf{C}_{2} \mathbf{D}_{2} \mathbf{C l}_{4}\right): \delta 153.6,150.1,139.5,130.0$, $129.8,129.2$, 129.1, 128.0, 127.5, 127.3, 126.7, 125.0, 124.7, 122.7, 119.2, 118.4, 112.4, 35.8, 32.0 ppm. HR-MS (ESI-MS): $\mathrm{m} / \mathrm{z}\left([\mathrm{M}+\mathrm{H}]^{+}\right)=$ 552.2435, calcd. for $\mathrm{C}_{40} \mathrm{H}_{30} \mathrm{~N}_{3}: \mathrm{m} / \mathrm{z}=552.2439$; error $=-0.72$ ppm. IR: $\tilde{v}$ $=2961,2908,758,692 \mathrm{~cm}^{-1}$.

General procedure for the protonation of PP-1 and PP-2 with triflic acid (TfOH)

In a NMR tube, a triflic acid (1.0 eq.) was added to a solution of PP-1 and PP-2 in $\mathrm{C}_{2} \mathrm{D}_{2} \mathrm{Cl}_{4}$. After the addition of $\mathrm{TfOH}$ and short mixing for two minutes, an unblemished colour change from yellow to red was observed. The reaction was carried out under ambient conditions. The NMR spectrum showed a shift of the signals. The corresponding HRMALDI-ToF confirmed the protonation and showed no decomposition.

PP-1+H+: ${ }^{1} \mathrm{H}-\mathrm{NMR}\left(300 \mathrm{MHz}, \mathrm{C}_{2} \mathrm{D}_{2} \mathrm{Cl}_{4}\right): \delta 8.58(\mathrm{~d}, \mathrm{~J}=8.1 \mathrm{~Hz}, 2 \mathrm{H}), 8.42$ $(\mathrm{d}, \mathrm{J}=8.3 \mathrm{~Hz}, 2 \mathrm{H}), 7.95(\mathrm{t}, \mathrm{J}=8.2 \mathrm{~Hz}, 1 \mathrm{H}), 7.75(\mathrm{~d}, \mathrm{~J}=7.0 \mathrm{~Hz}, 4 \mathrm{H}), 7.63$ - $7.36(\mathrm{~m}, 8 \mathrm{H}), 7.15(\mathrm{~d}, \mathrm{~J}=8.0 \mathrm{~Hz}, 2 \mathrm{H}), 7.03(\mathrm{t}, \mathrm{J}=7.7 \mathrm{~Hz}, 2 \mathrm{H}) \mathrm{ppm}$.
${ }^{13} \mathrm{C}-N M R\left(75 \mathrm{MHz}, \mathrm{C}_{2} \mathrm{D}_{2} \mathrm{Cl}_{4}\right): \delta 154.5,130.1,129.8,128.5,127.3,125.6$, $123.47,123.3,122.3,122.0 \mathrm{ppm}$. Unfortunately, not all carbon atoms could be detected due to the low solubility. HR-MS (MALDI-ToF): $\mathrm{m} / \mathrm{z}$ $\left([\mathrm{M}+\mathrm{H}]^{+}\right)=496.1876$, calcd. for $\mathrm{C}_{36} \mathrm{H}_{22} \mathrm{~N}_{3}: \mathrm{m} / \mathrm{z}=496.1813$; error $=12.69$ ppm.

PP-2+H+: ${ }^{1} \mathrm{H}-\mathrm{NMR}\left(\mathbf{3 0 0} \mathbf{M H z}, \mathrm{C}_{2} \mathrm{D}_{\mathbf{2}} \mathrm{Cl}_{4}\right): \delta 8.64(\mathrm{~s}, 2 \mathrm{H}), 8.49(\mathrm{~d}, \mathrm{~J}=8.2$ $\mathrm{Hz}, 2 \mathrm{H}), 7.76(\mathrm{~d}, \mathrm{~J}=7.5 \mathrm{~Hz}, 4 \mathrm{H}), 7.67-7.41(\mathrm{~m}, 8 \mathrm{H}), 7.08(\mathrm{dt}, \mathrm{J}=15.2$ $7.8 \mathrm{~Hz}, 4 \mathrm{H}), 1.56(\mathrm{~s}, 9 \mathrm{H}) .{ }^{13} \mathrm{C}-\mathrm{NMR}\left(75 \mathrm{MHz}, \mathrm{C}_{2} \mathrm{D}_{2} \mathrm{Cl}_{4}\right): \delta 154.5,133.4$, $131.9,129.8,129.6,127.9,126.4,122.8,118.6,33.3,31.6 \mathrm{ppm}$. Due to the low solubility in $\mathrm{C}_{2} \mathrm{D}_{2} \mathrm{Cl}_{4}$ chemical shifts of $13-\mathrm{C}$ nuclei were derived from the HMBC experiment. Unfortunately, not all carbon atoms could be detected. HR-MS (MALDI-ToF): $\mathrm{m} / \mathrm{z}([\mathrm{M}+\mathrm{H}]+)=552.2429$, calcd. for $\mathrm{C}_{40} \mathrm{H}_{30} \mathrm{~N}_{3}: \mathrm{m} / \mathrm{z}=552.2439$; error $=-1.81 \mathrm{ppm}$.

CCDC 1889654 (PP-2) contain the supplementary crystallographic data for this paper. This data can be obtained free of charge from The Cambridge Crystallographic Data Centre.

\section{Acknowledgements}

We thank the European Union's Horizon 2020 research and innovation program under grant agreement No 696656 (Graphene Flagship Core2), the German Research Foundation (DFG) within the Cluster of Excellence "Center for Advancing Electronics Dresden (cfaed)" and EnhanceNano (No. 391979941) as well as the European Social Fund and the Federal State of Saxony (ESF-Project "GRAPHD”, TU Dresden) for financial support. Furthermore, we thank F. Drescher, Dr. S. Machill, Prof. E. Brunner and Dr. T. Lübken for HR-MS measurements and NMR measurements, respectively, and Ulrike Nitzsche for the help with computational resources at IFW Dresden. We thank the Center for Information Services and High Performance Computing $(\mathrm{ZIH})$ at TU Dresden for generous allocations of compute resources.

Keywords: azomethine ylide • cycloaddition • heterocycles • polycyclic aromatic hydrocarbons $\cdot$ radical cations •

[1] a)M. Ball, Y. Zhong, Y. Wu, C. Schenck, F. Ng, M. Steigerwald, S. Xiao, C. Nuckolls, Acc. Chem. Res. 2015, 48, 267-276; b)X. Yan L.-s. Li, J. Mater. Chem. 2011, 21, 3295-3300; c)K. K. Baldridge, J. S. Siegel, Angew. Chem. Int. Ed. 2013, 52, 5436-5438; d)W Pisula, X. Feng, K. Müllen, Chem. Mater. 2011, 23, 554-567; e)Y. Morita S. Suzuki, K Sato, T. Takui, Nat Chem. 2011, 3, 197; f)Z. Sun, Q. Ye, C. Chi, J. Wu, Chem. Soc. Rev. 2012, 41, 7857-7889; g)W. Chen, X. Li, G. Long, Y. Li, R. Ganguly, M. Zhang, N. Aratani, H. Yamada, M. Liu, Q. Zhang, Angew. Chem. In. Ed. 2018, 57, 13555-13559; h)W. Chen, X. Li, G. Long, Y. Li, R. Ganguly, M. Zhang, N. Aratani, H. Yamada, M. Liu, Q. Zhang, Angew. Chem. 2018, 130, 13743-13747; i) J. Li, S. Chen, Z. Wang, Q. Zhang, Chem. Rec. 2016, 16, 1518-1530.

[2] a)R. Rieger, K. Müllen, J. Phys. Org. Chem. 2010, 23, 315-325; b)A. Narita, $X-Y$. Wang, X Feng, K Müllen, Chem Soc Rev. 2015, 44, 6616-6643; c)Z. Sun, J. Wu, J. Mater. Chem. 2012, 22 4151-4160; d)K. Kawasumi, Q. Zhang, Y. Segawa, L. T. Scott, K. Itami, Nat. Chem. 2013, 5, 739; e)P.-Y. Gu, Y. Zhao, J.-H. He, J. Zhang, C. Wang, Q.-F. Xu, J.-M. Lu, X. W. Sun, Q. Zhang, J. Org. Chem. 2015, 80, 3030-3035; f)P.-Y. Gu, Z. Wang, G. Liu, H. Yao, Z. Wang, Y. Li, J. Zhu, S. Li, Q. Zhang, Chem. Mater. 2017, 29 4172-4175.

[3] a)J. Cai, C. A. Pignedoli, L. Talirz, P. Ruffieux, H. Söde, L. Liang, V. Meunier, R. Berger, R. Li, X Feng, K Müllen, R. Fasel, Nat. Nanotechnol. 2014, 9, 896; b)H. Sahabudeen, H. Qi, B. A. Glatz, D. Tranca, R. Dong, Y. Hou, T. Zhang, C. Kuttner, T. Lehnert, G. Seifert, U. Kaiser, A. Fery, Z. Zheng, X. Feng, Nat. Commun 
2016, 7, 13461; c)L. Ji, A. Friedrich, I. Krummenacher, A Eichhorn, H. Braunschweig, M. Moos, S. Hahn, F. L. Geyer, O. Tverskoy, J. Han, C. Lambert, A. Dreuw, T. B. Marder, U. H. F. Bunz, J. Amer. Chem. Soc. 2017, 139, 15968-15976; d)M. Richter K. S. Schellhammer, P. Machata, G. Cuniberti, A. Popov, F. Ortmann, R. Berger, K. Müllen, X. Feng, Org. Chem. Front. 2017 4, 847-852; e)M. Gsänger, J. H. Oh, M. Könemann, H. W. Höffken, A.-M. Krause, Z. Bao, F. Würthner, Angew. Chem. Int. Ed. 2010 49, 740-743; f)M. Gsänger, J. H. Oh, M. Könemann, H. W Höffken, A.-M. Krause, Z. Bao, F. Würthner, Angew. Chem. 2010 122, 752-755; g)A. Mateo-Alonso, Chem. Soc. Rev. 2014, 43 6311-6324; h)A. Hirsch, B. Nuber, Acc. Chem. Res. 1999, 32, 795 804; i)Z. Wang, P. Gu, G. Liu, H. Yao, Y. Wu, Y. Li, G. Rakesh, J. Zhu, H. Fu, Q. Zhang, Chem. Commun. 2017, 53, 7772-7775.

[4] a)U. H. F. Bunz, Acc. Chem. Res. 2015, 48, 1676-1686; b)U. H. F. Bunz, J. U. Engelhart, Chem. - Eur. J. 2016, 22, 4680-4689; c)R Tang, F. Zhang, Y. Fu, Q. Xu, X. Wang, X. Zhuang, D. Wu, A Giannakopoulos, D. Beljonne, X. Feng, Org. Lett. 2014, 16, 47264729

a)M. Takase, T. Narita, W. Fujita, M. S. Asano, T. Nishinaga, $\mathrm{H}$. Benten, K. Yoza, K. Müllen, J. Amer. Chem. Soc. 2013, 135, 8031 8040; b)S. Higashibayashi, P. Pandit, R. Haruki, S.-i. Adachi, R Kumai, Angew. Chem. Int. Ed. 2016, 55, 10830-10834; c)S.
Higashibayashi, P. Pandit, R. Haruki, S.-i. Adachi, R. Kumai, Angew. Chem. 2016, 128, 10988-10992.

[6] a) H. Wang, T. Maiyalagan, X. Wang, ACS Catal. 2012, 2, 781-794 b)D. Wei, Y. Liu, Adv. Mater. 2010, 22, 3225-3241.

[7] R. Berger, M. Wagner, X. Feng, K. Müllen, Chem.Sci. 2015, 6, 436-441.

[8] a)X.-Y. Wang, M. Richter, Y. He, J. Björk, A. Riss, R. Rajesh, M. Garnica, F. Hennersdorf, J. J. Weigand, A. Narita, R. Berger, X. Feng, W. Auwärter, J. V. Barth, C.-A. Palma, K. Müllen, Nat Commun. 2017, 8, 1948; b)S. Ito, Y. Tokimaru, K. Nozaki, Chem. Commun. 2015, 51, 221-224.

[9] a)M. Richter, S. Hahn, E. Dmitrieva, F. Rominger, A. Popov, U. H. F. Bunz, X. Feng, R. Berger, Chem. - Eur. J. 2019, 25, 1345-1352 b)Y. Tokimaru, S. Ito, K. Nozaki, Angew. Chem. Int. Ed. 2017, 56, 15560-15564; c)Y. Tokimaru, S. Ito, K. Nozaki, Angew. Chem. 2017, 129, 15766-15770; d)Y. Tokimaru, S. Ito, K. Nozaki, Angew. Chem. Int. Ed. 2018, 57, 9818-9822; e)Y. Tokimaru, S. Ito, K Nozaki, Angew. Chem. 2018, 130, 9966-9970.

G. A. Crosby, J. N. Demas, J. Phys. Chem. 1971, 75, 991-1024.

B. König, Angew. Chem. 1996, 108, 115-116.

F. Neese, WIREs Comput. Mol. Sci. 2012, 2, 73-78.

S. Stoll, A. Schweiger, J. Magn. Res. 2006, 178, 42-55. 
Entry for the Table of Contents (Please choose one layout)

\section{COMMUNICATION}

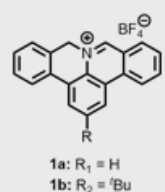

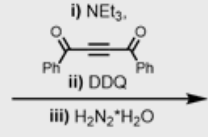

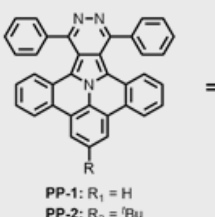

$=$

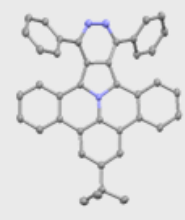

M. Richter, Y. Fu, E. Dmitrieva,

J. J. Weigand, A. Popov, R. Berger,

J. Liu, X. Feng *

Page No. - Page No.

A Polycyclic Aromatic Hydrocarbon Containing A Pyrrolopyridazine Core

Polycyclic aromatic hydrocarbons (PAHs) with a pyrrolopyridazine (PP-1 and PP-2) core have been synthesized by 1,3-cycloaddition of polycyclic aromatic azomethine ylides (PAMYs) and 1,4-diphenylbut-2-yne-1,4-dione as dipolarophile as well as subsequent condensation reaction with hydrazine. The properties were investigated by single-crystal X-ray analysis, UV-Vis absorption spectroscopy, cyclic voltammetry and computational modeling. Furthermore, the radical cation species of the tert-butyl-substituted PP-2 was obtained by EPR/UV-Vis-NIR spectroelectrochemistry. 